\title{
Práticas pedagógicas e formação docente intermediadas nos encontros com os bebês
}

\begin{abstract}
Resumo: No bojo da articulação entre formação de professores e as demandas do trabalho pedagógico na educação infantil, este artigo focaliza como os bebês interagem com as propostas de práticas pedagógicas. Nessa perspectiva, desenvolve a pesquisa qualitativa exploratória, sustentada em referenciais bakhtinianos, contando também com a interlocução com Certeau (2010) em uma sala do Grupo I (crianças de até um ano e onze meses), de um Centro Municipal de Educação Infantil localizado na região da Grande Vitória, do Estado do Espírito Santo. A pesquisa investiga as especificidades do brincar dos bebês, com vistas a propor outras atividades mobilizadoras dos movimentos expressivos e criativos das crianças. Com base nas Diretrizes Curriculares Nacionais da Educação Infantil (Dcneis), que apontam, como eixos do trabalho docente com as crianças, a interação e a brincadeira, as práticas perspectivadas envolviam os jogos dramáticos almejando proporcionar experiências com diversos tipos de linguagens e expressões. Como resultado, a pesquisa assinala que os encontros com os bebês movem também a formação docente, evidenciando novos elementos para a proposição de práticas pedagógicas com as crianças pequenas.
\end{abstract}

Palavras-chave: Educação infantil; Práticas pedagógicas; Formação docente; Trabalho docente com bebês.

\section{Pedagogical practices and teaching training intermediate in the meetings with babies}

Abstract: This article focuses on the interaction between teacher training and the demands of pedagogical work in early childhood education. In this perspective, he develops the exploratory qualitative research, based on Bakhtinian references, also with the dialogue with Certeau (2010) in a room of Group one (children up to one year and eleven months), at Municipal Infant Education Center located in Region of Greater Vitória, in the State of Espírito Santo. The research investigates the specificities of babie's play, with a view to proposing other activities that mobilize the expressive and creative movements of the children. Based on the National Curriculum Guidelines for Early Childhood Education, which point out, as the axes of teaching work with children, interaction and play, envisaged practices involved dramatic games aiming to provide experiences with different types of languages and expressions. As a result, the research indicates that the meetings with the babies also move the teacher training, evidencing new elements for the proposition of pedagogical practices with the young children.

Keywords: Child education; Pedagogical practices; Teacher training; Teaching work with babies.

\footnotetext{
'Graduado em Pedagogia pela Universidade Federal do Espírito Santo (UFES); egresso do Programa de Educação Tutorial Conexões de Saberes: Projeto Educação (PET EDU); Mestrando em Psicologia Institucional no PPGPSI (UFES). E-mail: elyrrandro@hotmail.com ${ }^{2}$ Doutora em Educação pela Universidade Federal Fluminense (UFF); professora do Departamento de Linguagens, Cultura e Educação e do Programa de Pós-Graduação em Educação, do Centro de Educação, da Universidade Federal do Espírito Santo (DLCE/PPGE/CE/UFES); coordenadora do Grupo de Pesquisa "Formação e Atuação de Educadores" (GRUFAE/UFES); tutora do Programa de Educação Tutorial: Projeto Educação (PETEDU/UFES). E-mail:valdetecoco@hotmail.com
} 


\section{Introdução}

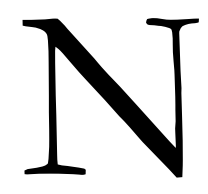

este artigo, focalizamos as práticas pedagógicas com bebês em articulação com os processos formativos dos docentes. Essa articulação foi mobilizada na aproximação entre as atividades de pesquisa e de extensão, vinculadas ao desenvolvimento de um grupo de educação tutorial, denominado Programa de Educação Tutorial Conexões de Saberes: Projeto Educação (PET EDU). Nesse quadro, cabe inicialmente informar que o PET EDU integra graduandos dos cursos de Pedagogia, Artes Visuais e Educação Física, desenvolvendo atividades de ensino, pesquisa e extensão voltadas à formação de professores no campo da educação infantil. Seu desenvolvimento está vinculado a um grupo de pesquisa, de modo que graduandos e pós-graduandos interagem no desenvolvimento das atividades.

Assim, como integrantes do PET EDU, no desenvolvimento das atividades de extensão articuladas à pesquisa, fomos acolhidos em uma turma de bebês ${ }^{3}$ (Grupo 1), possibilitando investigar proposição de práticas pedagógicas endereçadas às demandas das crianças pequenas. Como aponta Barbosa (2010, p.11):

Uma das características de uma turma de bebês é que mesmo quando a professora tem uma proposta muito interessante os bebês geralmente não participam dela como grupo completo, ou ao menos não ficam presentes em sua totalidade. Sempre há um bebê que está com sono, outro que precisa ser trocado. Assim, aquilo que denominamos trabalho diversificado é uma constante na turma de bebês.

Então, parece haver uma dificuldade de manter o grupo unido, realizando a mesma atividade de modo cooperativo, tensionando uma "cultura escolar" (FARIA FILHO, 2004) que evidencia lógicas modelares de aula, em que o professor ensina e a criança aprende, em um processo, aparentemente, de passividade e aceitação por parte dos estudantes. Com isso, o autor chama a atenção para a necessidade de se pensar em práticas que se adaptem às crianças pequenas, observando, em especial, suas formas próprias de participação no curso das ações educativas. Como diz Spolin (1979, p. 9), "[...] trabalhe com o aluno onde ele está, não onde você pensa que ele deveria estar", pois cada grupo apresenta exigências particulares aos docentes.

Nesse sentido, no escopo do trabalho educativo com os bebês, o brincar e as diversas linguagens artísticas, assim como a interação, que são eixos que direcionam as atividades realizadas na educação infantil, como apontam as Diretrizes Curriculares Nacionais para a Educação Infantil (Dcneis), podem se constituir no ponto de partida deste trabalho. Acreditamos que "[...] as propostas pedagógicas dirigidas aos

3Para esta pesquisa, nossas referências aos bebês implicam o trabalho realizado com um grupo de crianças com idades variando de um ano até um ano e onze meses, em função da organização dos agrupamentos etários da instituição pesquisada. 
bebês devem ter como objetivo garantir as crianças acesso aos processos de apropriação, renovação e articulação de diferentes linguagens" (BARBOSA, 2010, p.5).

Sendo assim, delineamos uma pesquisa observando a possibilidade de articulação com a arte, como meio de comunicação com os bebês. Ficamos atentos à ideia de que a arte é "[...] um tipo especial de comunicação que possui uma forma própria" (VOLOCHÍNOV, 2013, p. 76) para nos movermos em direção às crianças. Buscamos proporcionar vivências valorizando o aprendizado por meio da experiência estética.

Vigotski (2009) nos mostra que a capacidade de desenvolver pensamentos abstratos, ou seja, a imaginação é o que nos diferencia do resto do reino animal. É uma capacidade fundamental para o desenvolvimento da humanidade. Para ele, “[...] toda obra da imaginação constrói-se sempre de elementos tomados da realidade e presentes na experiência anterior da pessoa" (p.20). Nesse sentido, "[...] a conclusão pedagógica a que se pode chegar com base nisso consiste na afirmação da necessidade de ampliar a experiência da criança, caso se queira criar bases suficientemente sólidas para a sua atividade de criação" (p. 20).

Partindo do interesse de desenvolver práticas pedagógicas para os bebês, acreditando que a experiência estética é uma potente ferramenta didática, buscamos entender: que tipos de práticas docentes são mais interessantes e atrativas para os bebês, visando a potencializar a expressão individual e coletiva, a criatividade e a capacidade de cooperar com os colegas? Com essa indagação, almejamos compreender como os bebês recepcionam as práticas docentes recorrentes no cotidiano de uma instituição de educação infantil. Nesse processo, procuramos observar como interagem com os colegas e com o docente. Com isso, outros questionamentos se apresentaram à pesquisa: como os bebês realizam as atividades propostas pelos docentes? Como os bebês participam de atividades em grupo? Como se dá a interação entre os bebês nos momentos de atividades em grupo?

A partir desses questionamentos, o objetivo da pesquisa se voltou para as práticas docentes com os bebês de uma instituição formal de educação infantil da Grande Vitória ${ }^{4}$ do Estado do Espírito Santo. Nesse contexto de articulação com o processo de formação de professores, investigamos as práticas docentes realizadas ao mesmo tempo em que propusemos novas práticas, tendo, como objetivos específicos, a proposta de observar como se organizam os bebês nas atividades em sala, sugerir e participar de jogos e dinâmicas teatrais, com o intuito de potencializar a expressão individual, coletiva e a criatividade, adequando, sempre que necessário, as atividades à observação dos modos de brincar dos bebês.

Para essa empreitada, tivemos Bakhtin $(2011,2012)$ como referencial teórico do campo da linguagem, agregando inspirações em assertivas de Boal (2008), Slade (1978) e Spolin (1979) para a elaboração das atividades, em especial, no propósito de valorizar experiências estéticas com os bebês. Também dialogamos com Vigotski (2009), da área da psicologia, observando a experiência lúdica como potência no desenvolvimento da criatividade das crianças. Refletimos ainda sobre o conceito de táticas de

${ }^{4}$ Região metropolitana do Estado. 
Certeau (2011) para captar os protagonismos das crianças na negociação com os adultos para o encaminhamento do curso do trabalho educativo. Nesse quadro, tomamos o conceito de arte como meio de comunicação e produto social, conforme proposição de Volochínov (2013). Com esses referenciais, delineamos a pesquisa qualitativa e exploratória (MOREIRA; CALEFFE, 2008) como orientadora dos nossos encontros com os bebês e seus docentes, conforme apresentaremos no tópico que segue.

\section{Pressupostos teórico-metodológicos da pesquisa}

Com o intuito de realizar práticas outras, ${ }^{5}$ a preocupação inicial foi desenvolver atividades que respeitassem os bebês, fazendo com e não para eles. O trabalho se desenvolveu ancorado numa perspectiva qualitativa e exploratória, por entender que essa abordagem possibilita uma visão geral, de tipo aproximativo, acerca do fenômeno (MOREIRA; CALEFFE, 2008), neste caso, a complexidade do trabalho com os bebês. Os dados produzidos, resultantes das atividades realizadas, foram registrados em diário de campo e relatórios ( $\mathrm{R} \mathrm{E})$, conforme os encontros com a turma.

Por questões éticas, não identificamos as crianças e nem os profissionais envolvidos, buscamos, sobretudo, compor os relatos com as descrições de nossos movimentos junto dos bebês, instando um processo avaliativo do percurso formativo decorrente das ações. Esse movimento de posicionamento no campo e de produção de análises tinha como objetivo, na ancoragem bakhtiniana, o exercício de fortalecer uma posição de escuta. As práticas se constituíram em um constante processo de reflexão - ação reflexão, aliado ao conceito de excedente de visão, no qual compreendemos que:

Eu devo entrar em empatia com esse outro indivíduo, ver axiologicamente o mundo de dentro dele tal qual ele o vê, colocar-me no lugar dele e, depois retornado ao meu lugar, completar o horizonte dele com o excedente de visão que desse meu lugar se descortina fora dele, convertê-lo, criar para ele um ambiente concludente a partir desse excedente da minha visão, do meu conhecimento, da minha vontade e do meu sentimento (BAKHTIN, 2011, p. 23).

Esse conceito auxiliou nossos investimentos na comunicação com os bebês, pois, na busca de construir uma prática com eles, fez-se necessário dialogar, tentando, embora nem sempre conseguindo, colocar-nos no lugar do outro. Do mesmo modo, permanecemos atentos às táticas (CERTEAU, 2011) utilizadas pelos bebês na interação conosco, em especial, aquelas que poderiam sinalizar uma rejeição às nossas propostas. Enfim, estabelecemos relações sociais (PINO, 2005) com os bebês, situadas no contexto de uma instituição de educação infantil e, portanto, precisávamos estar atentos aos seus assentimentos. Nesse processo interativo, observamos que as táticas desenvolvidas na negociação do curso das ações foram muitas, em que se destacam, como exemplos de adesão, a aproximação, o toque e a solicitação e, como exemplos de manifestação de discordâncias, jogar-se no chão e se encolher, correr para longe etc. Para além dos dualismos entre adesão e discordâncias, cabe observar um rico movimento

${ }^{5}$ Para Bakhtin não existe nem primeira nem última palavra, ou seja, não podemos afirmar que as atividades propostas são totalmente novas para os bebês, ou que são o "início" de algo novo. Por isso utilizamos o termo outras, por entender que essas são apenas atividades diferentes das habituais e que se tornam únicas no evento de serem desenvolvidas por tais sujeitos. 
comunicativo, não sem silenciamentos e formas de calar, que indica a complexidade de vivificar o cotidiano com o reconhecimento da participação ativa dos bebês.

Para encaminhar esse processo de negociação, a escolha das ações se deu embasada no fato de que, na educação infantil, as práticas docentes devem garantir experiências que "Favoreçam a imersão das crianças nas diferentes linguagens e o progressivo domínio por elas de vários gêneros e formas de expressão: gestual, verbal, plástica, dramática e musical" (BRASIL, 2010, p.25), de modo a promover, “[...] o relacionamento e a interação das crianças com diversificadas manifestações de música, artes plásticas e gráficas, cinema, fotografia, dança, teatro, poesia e literatura".

Nesse contexto, escolhemos atividades que envolvessem as diferentes linguagens artísticas, pois "Nenhum dos signos ideológicos específicos, fundamentais, é inteiramente substituível por palavras. É impossível, em última análise, exprimir em palavras, de modo adequado, uma composição musical ou uma representação pictórica" (BAKHTIN, 2012, p. 38).

Sendo assim, é necessário que os bebês tenham contato com diferentes tipos de experiências estéticas, pois cada uma é única. Nesse sentido, empregamos o pressuposto de que "A arte é também eminentemente social. O meio social extra-artístico, a influenciar a arte desde o exterior, encontra nela uma resposta imediata e interna. $\mathrm{Na}$ arte, o que não é alheio atua sobre o alheio, e uma formação social influencia sobre outra" (VOLOCHÍNOV, 2013, p. 74). Como elemento social, ela também se caracteriza como um meio de comunicação.

Esta comunicação artística cresce sobre a base comum para todas as formas sociais, mas conserva, sem esforço, igual às demais formas sociais, sua singularidade: trata-se de um tipo especial de comunicação que possui uma forma própria, característica somente deste tipo (VOLOCHÍNOV, 2013, p. 76).

Com isso, defendemos que a arte pode e deve ser acessível a todos, por ser eminentemente social, nascida da mesma base social que todos os outros gêneros discursivos. Como aponta Volochínov (2013, p. 88), “[...] uma obra artística é um potente condensador de valorações sociais não expressadas [...]”, ou seja, ela é moldada conforme o "horizonte social" (BAKHTIN, 2012) no qual está inserida. Sendo assim, começamos pelo teatro, pois entendemos que a linguagem corporal pode se constituir como meio potente de interação com os bebês. Como citado, a educação infantil deve promover o contato da criança com diversos tipos de expressão, logo, com efeito para este trabalho, entendemos expressão como "[...] tudo aquilo que, tendo se formado e determinado de alguma maneira no psiquismo do indivíduo, exterioriza-se objetivamente para outrem com a ajuda de algum código de signos exteriores” (BAKHTIN, 2012, p. 115). Para justificar nossa escolha por começar pelo teatro, apresentamos uma breve explicação sobre os jogos dramáticos e as bases epistemológicas que sustentam essa prática. 


\section{Os jogos dramáticos}

Para compor as dinâmicas ou jogos dramáticos com os bebês, buscamos inspiração nos exercícios de Augusto Boal' (2008) e auxílio nas reflexões de Peter Slade (1978) e Viola Spolin ${ }^{8}$ (1979). Considerando o pressuposto de fazer os bebês mote de nossa proposição de pesquisa, ficou evidente a importância de cuidar para que as deliberações não se constituíssem como "material pronto" para ser executado. Isso foi facilitado pelo papel ativo dos bebês. Nós é que escolhemos como executar as proposições e muitas vezes as modificamos para que melhor se adaptem ao nosso contexto, criando, assim, novas ações inspiradas em outras. Com Bakhtin (2011, p. 410) cabe destacar que

Não existe a primeira nem a última palavra, e não há limites para o contexto dialógico (este se estende ao passado sem limites e ao futuro sem limites). Nem os sentidos do passado, isto é, nascidos do diálogo dos séculos passados, podem jamais ser estáveis (concluídos, acabados de uma vez por todas): eles sempre irão mudar (renovando-se) no processo de desenvolvimento subsequente, futuro do diálogo.

Sendo assim, no sentido bakhtiniano, nosso discurso, ou prática, é atravessado por inúmeros outros discursos. É importante elucidar que o que foi realizado eram jogos dramáticos e não teatrais, pois o termo teatro (de origem grega) significa lugar onde se vê, passando a ideia de que o nosso objetivo seria apenas apresentaras crianças para um público, porém o nosso trabalho se trata justamente do contrário, daí a necessidade de se utilizar o termo drama (palavra também de origem grega) que significa eu faço, eu luto, termo que confere autonomia às crianças, sem a preocupação de apresentá-las a alguém.

A diferenciação entre drama e teatro reflete na realidade a preocupação em resguardar a espontaneidade na representação. A oposição ao teatro é sempre fundamentada nos aspectos formais que o espetáculo impõe à atuação e que são exteriores à criança. $\mathrm{O}$ aluno que simplesmente decora um texto clássico e o espetáculo que se preocupa apenas com a produção não refletem valores educacionais, se o sujeito da representação não foi mobilizado para uma ação espontânea. Mas a visão puramente espontaneísta também corre o risco de reduzir a proposta de educação artística a objetivos meramente psicológicos, o que afasta a possibilidade de entender a arte como forma de conhecimento (KOUDELA, 2011, p.25).

Nesse sentido, nos jogos dramáticos:

Todos são fazedores, tanto ator como público, indo para onde querem e encarando qualquer direção que lhes apraz durante o jogo. A ação tem lugar por toda parte em volta de nós e não existe a questão de 'quem deve representar para quem e quem deve ficar sentado vendo quem fazendo o quê!' É uma experiência viril e excitante, na qual a tarefa do professor é a de aliado amoroso (SLADE, 1978, p. 18).

Segundo Slade (1978), o jogo dramático pode ser projetado (utilizando brinquedos e objetos comuns) ou pessoal (utilizando o próprio corpo). Quando a criança brinca com um boneco ou um carrinho, ela também está interpretando.

${ }^{6}$ Diretor e teórico brasileiro do teatro que desenvolveu suas dinâmicas com adultos.

7Pedagogo inglês que utilizava os jogos teatrais de modo instrumental. Desenvolveu trabalhos com crianças de cinco anos em diante.

${ }^{8}$ Atriz norte-americana e criadora de um método próprio de jogos dramáticos voltados para adultos e crianças. 
Buscamos com isso potencializar a capacidade de autoexpressão (SPOLIN, 1979) e a criatividade dos bebês, habilidades latentes em todo o ser humano, pois "A imaginação dramática está no centro da criatividade humana e, assim sendo, deve estar no centro de qualquer forma de educação [...]" (KOUDELA, 2011, p.28).

Permanecemos em vigilância para não esboçarmos manifestações que pudessem desencorajar as crianças, pois,

Abandonados aos julgamentos arbitrários dos outros, oscilamos diariamente entre o desejo de ser amado e o medo da rejeição para produzir. Qualificados como ‘bons' ou 'maus' desde o nascimento (um bebê 'bom' não chora) nos tornamos tão dependentes da tênue base de julgamento de aprovação/desaprovação que ficamos criativamente paralisados. Vemos com os olhos dos outros e sentimos o cheiro com o nariz dos outros (SPOLIN, 1979, p.6).

Endossamos a perspectiva bakhtiniana com a fala de Spolin ao dizer:

[...] avaliamos a nós mesmos do ponto de vista dos outros, através do outro procuramos compreender e levar em conta os momentos transgredientes à nossa própria consciência: desse modo, levamos em conta o valor da nossa imagem externa do ponto de vista da possível impressão que ela venha a causar no outro [...] (BAKHTIN, 2011, p. 13).

Nesse sentido, é fundamental ter cuidado com a postura que tomamos em frente aos bebês, já que queremos potencializar a capacidade criativa deles e não inibi-la, assim o encorajamento e o estímulo se tornam importantes no processo interativo. Acreditamos que

A melhor brincadeira teatral infantil só tem lugar onde oportunidade e encorajamento lhe são conscientemente oferecidos por uma mente adulta. Isto é um processo de 'nutrição' e não é o mesmo que interferência. É preciso construir a confiança por meio da amizade e criar a atmosfera propícia por meio de consideração e empatia (SLADE, 1978, p. 18).

Assim, com essas bases epistemológicas, movemo-nos no campo de pesquisa, permitindo compor ações partilhadas com os bebês e produzir análises associadas. Numa perspectiva bakhtiniana, partimos do pressuposto de que os atos de troca verbal ou cultural afetam os interlocutores (STAM, 1993), instando os processos formativos dos docentes no cotidiano com os bebês.

\section{No cotidiano com os bebês}

A pesquisa foi realizada em um período de três meses (de setembro a novembro no ano de 2014), com encontros semanais na instituição de educação infantil, abarcando um turno completo de trabalho com as crianças (da chegada à saída). Para facilitar a comunicação das análises, no escopo da vinculação entre as práticas pedagógicas e a formação docente, organizamos a apresentação dos dados numa linearidade do desenvolvimento temporal da pesquisa.

Todavia, cabe destacar que os processos formativos não se efetivam em temporalidades determinadas, movendo recuos e avanços na produção de novas compreensões. Nessa lógica, 
selecionamos eventos que retratam os diferentes espaços de participação dos bebês incluindo ações desenvolvidas na sala de atividades, vivências do grupo no pátio, apresentação em atividade conjunta da instituição e participação em festas e comemorações. Com esses eventos, movemos a pesquisa analisando não as práticas pedagógicas encaminhadas com as crianças pequenas, mas, muito especialmente, os nossos processos formativos mobilizados nos encaminhamentos dessas práticas com os bebês. Em síntese, os encontros com os bebês não só materializaram nossas intenções de trabalho conjunto mas, sobretudo, afetaram nossos processos formativos.

Assim sendo, começamos por retomar os dados do momento de chegada no Grupo 1:

Como combinado anteriormente com a diretora e a pedagoga, começamos as atividades de extensão no Grupo 1 [...]. A professora nos recebeu bem, mostrando-se aberta à realização de propostas compartilhadas e atividades novas. A turma tem um total de 12 crianças, mas 3 haviam faltado nesse dia. Os bebês estão bem desenvolvidos na parte motora, andam e falam algumas palavras (RE; 14 de setembro de 2014).

Para o começo da inserção no grupo, não preparamos nem planejamos conjuntamente com a professora propostas de atividades; decidimo-nos a conhecer o grupo, a professora, as funcionárias, o cotidiano da instituição etc. Lembramos o pressuposto de ancoragem da pesquisa, de considerar os bebês como sujeitos ativos e capazes, pois, como aponta Barbosa (2010, p. 3), "[...] quando as crianças são tomadas como seres capazes elas se tornam protagonistas no projeto educacional". Sendo assim, trabalhamos com a ideia de que precisávamos nos preparar para os encontros com as crianças e não preparar esses encontros.

Ainda que esses referenciais fossem tomados como suporte à pesquisa e, consequentemente, ao processo formativo dos pesquisadores, os dados dos momentos iniciais de inserção no campo informam que as características do grupo ainda podem ser consideradas como desafios ao trabalho docente:

[...] a grande questão é que elas, as crianças, não conseguem manter a atenção em uma atividade só, muito menos em grupo, elas se dispersam com muita facilidade. Quando a professora se dá conta, cada criança está envolvida em uma atividade diferente. Parece um desafio que precisa ser contornado pelo professor, pois, com cada criança em um espaço diferente, fica difícil de realizar atividades na/com a turma; é preciso unir os 'bebês' em uma atividade conjunta (R E; 14 de setembro de 2014).

Esse registro informa que, por mais que o protagonismo dos bebês fosse um pressuposto afirmado, ainda se mostrava presente a expectativa da possibilidade de que todos executassem, ao mesmo tempo, uma atividade ou, de outro modo, da impossibilidade de conseguir realizar uma atividade comum com o grupo. Cabe ponderar que

Muitas vezes as pessoas pensam que os bebês têm pouca capacidade de atenção, de envolvimento, de curiosidade e por este motivo não oferecem propostas de atividades para as crianças, ou, ao contrário, trocam a cada momento as propostas. Ora, quando temos efetivamente contato com os bebês e os observamos brincando sozinhos ou com outros bebês, verificamos que eles ficam intrigados e envolvidos com uma tarefa e podem permanecer assim por muito tempo. A pressa em geral é nossa, dos adultos (BARBOSA, 2010, p. 8).

Assim, as análises dos registros mais iniciais da pesquisa informam que a ancoragem epistemológica favoreceu o tensionamento das observações e ações que muitas vezes se mostravam presas 
a paradigmas que não correspondiam à realidade complexa do trabalho educativo com os bebês. Então, de partida, reiteramos que o eixo da formação toma destaque no estudo, ressignificando o próprio movimento da pesquisa em direção aos bebês.

Nessa trajetória de pesquisa e, muito especialmente, de formação, após nossa ambientação, buscamos avançar nos processos interativos com os bebês, inserindo-nos na realização de uma atividade com as crianças. A atividade planejada era bem simples, buscava exercitar um movimento de cooperação no grupo. O exercício consistia em formar um círculo com as mãos dadas, depois uma das crianças passaria por baixo das mãos dadas, embolando o círculo. Logo em seguida, elas retornariam a roda em seu estado inicial. Com essa proposta, acreditávamos que poderíamos realizar com os bebês movimentos diferentes dos usuais vivenciados na sala, compondo e recompondo formas com nossos corpos. Contudo "a atividade foi um fracasso", ainda que as crianças fossem receptivas à nós (pesquisadores, professora e auxiliar), parece-nos que as ações não ganharam a adesão delas, que mostraram outros interesses, em especial, "deitar no chão e correr" (R E; 22 de setembro de 2014).

No estudo e análise dessa primeira experiência, algumas conclusões importantes foram obtidas. A primeira é que os bebês participam melhor de uma atividade se a professora e as auxiliares também participarem, logo, propor uma atividade implica considerar sua compatibilidade de execução a todos os sujeitos. Por exemplo, na dinâmica sugerida não havia condições de a professora passar por baixo dos bebês, e o nosso erro foi propor uma nova atividade sem a participação dos adultos. Então, o envolvimento no fazer comum nos pareceu uma atitude importante para mediar a ação com os bebês.

A segunda conclusão é relativa ao processo de preparação, em especial, considerando as formas de mover os convites ao engajamento dos bebês, observando que ações de comando não garantem o envolvimento, por mais interessantes que sejam as propostas. Nesse movimento, é importante observar os processos de recusas para além de uma negativa oral, captando as sutilezas dos afastamentos, da expressão de outros interesses etc. Cabe também concluir sobre a temporalidade das ações e as demandas que geram para as crianças, avaliando, em especial, as estratégias que utilizamos para encaminhar orientações e explicações (geralmente muito demoradas para as crianças). Por vezes, vemos os bebês iniciar as ações em experimentações muito particulares, antes mesmos das nossas explicações, do esclarecimento do que estávamos propondo com determinados objetos.

Continuando com a narrativa da nossa experiência de "fracasso", cabe ainda destacar a importância - e as possibilidades - de reposicionar o curso das ações, quando estamos sensíveis às demandas das crianças.

[...] a professora interveio rápido. Assim que percebemos o estresse das crianças ela começou a cantar uma música e puxou uma nova atividade, no caso, 'a galinha do vizinho'. Um movimento diferente foi se estabelecendo e as crianças foram se engajando, participando, sem reclamações, talvez por elas já conhecerem a brincadeira, talvez por ser uma atividade mais musical, enfim, uma coisa ficou clara, é preciso criar toda uma estratégia para atrair os bebês para uma atividade, ou seja, preparar o terreno e a música parece ser uma ferramenta bem útil (R E; 22 de setembro de 2014). 
De todo modo, cabe ainda considerar a avaliação do processo de inserção de pesquisadores no grupo. Por mais que estivéssemos observando a aceitação e interação, essa experiência pode ainda informar que talvez fosse ainda muito cedo para propor algo com os bebês, indagando se eles estavam suficientemente próximos de nós, em particular, quais os elos de confiança que tínhamos estabelecido. Ainda assim, cabe também considerar a importância e o espaço que os bebês tiveram para mostrar seus posicionamentos e vontades, naquele momento, entendidos como recusas às proposições em curso.

Com essa desventura a vivificar a pesquisa, permanecemos no circuito cotidiano da turma, ajudando a alimentar os bebês, a limpar, a cuidar etc. Não que não fizéssemos isso antes, porém queríamos reforçar a nossa presença nessas práticas, buscando um olhar aproximado a cada um/a, captando formas mais sutis de diálogo e de mobilização de convites ao trabalho partilhado.

Aproximando o dia da mostra cultural, uma atividade coletiva e ampliada da instituição, avançamos em nossos investimentos de integração ao grupo. Nesses investimentos, foi possível reposicionar nossas primeiras conclusões a respeito do par aproximação às crianças e possibilidades de engajamento nas proposições.

[...] parece complicado preparar qualquer apresentação com os bebês, digo, qualquer apresentação com a organização e a lógica que o adulto deseja. [...] eles não se adéquam à forma do adulto de pensar e de organizar o espaço, e será que deveriam? (R. E; 29 de setembro de 2014).

$\mathrm{Na}$ atenção aos movimentos dos bebês, avançando no nosso processo formativo, foi possível captar que não basta só estar próximo dos bebês para que eles participem. Ainda que esse seja um requisito importante, as ações propostas precisam ser negociadas. Em mais uma de nossas experiências de pesquisa, foi possível observar ainda:

Durante a tarde, a professora levou a turma para o pátio. Nesse momento deu pra perceber o quanto o bebê é fascinado pela 'aventura', no sentido de descobrir coisas [...]. Eles adoram pegar a terra, as folhas, as pedras ou qualquer outra coisa que está ao seu redor.Ficam um tempo encarando o objeto para em seguida, jogá-lo no chão e procurar coisas novas (R E; 29 de setembro de 2014).

O relato anterior apresentou para nosso processo de pesquisa - e de formação - uma importante pista para o trabalho com os bebês. É preciso aproveitar o interesse e embarcar na curiosidade dos pequenos. Na negociação das proposições, considerar as formas próprias de apropriação dos objetivos das ações. Por exemplo, na apresentação da mostra cultural, por vezes ensaiada, tivemos crianças que dançaram com muita desenvoltura dando um verdadeiro "show" (na assertiva dos adultos),que correram para o colo dos pais, que ficaram paradas etc. No quadro de propostas de apresentação de crianças, é preciso observar que

[...] a criança é um péssimo ator para os outros, mas um maravilhoso ator para si mesma, e todo o espetáculo deve ser organizado de tal forma que todas as crianças sintam que estão interpretando para si mesmas, que sejam envolvidas pelo interesse na interpretação em si, pelo processo de interpretar, e não pelo resultado final (VIGOTSKI, 2009, p.102). 
Então, no cotidiano das atividades das instituições, cabe observar o cuidado na proposição desses momentos de apresentações, revisitando a conceituação de criança das Dcneis:

Sujeito histórico e de direitos que, nas interações, relações e práticas cotidianas que vivencia, constrói sua identidade pessoal e coletiva, brinca, imagina, fantasia, deseja, aprende, observa, experimenta, narra, questiona e constrói sentidos sobre a natureza e a sociedade, produzindo cultura (BRASIL, 2010, p. 12).

Assim, destacamos o direito da criança de não querer participar desse tipo de apresentação, ou melhor, de conduzir sua forma própria de participar e avaliar esses momentos.

Essas análises precisam também ser articuladas às reflexões sobre o trabalho docente na educação infantil. Advogar processos formativos para os professores instados no reconhecimento das crianças pequenas como partícipes do trabalho educativo em curso não implica responsabilizá-los isoladamente pelas decisões que se efetivam nos contextos institucionais. É importante não desconsiderar as pressões dos familiares e da comunidade, que querem ver as crianças "produzindo", da gestão da instituição, que é cobrada por "eficiência", da avaliação social que cada vez mais vem impondo expectativas de processos de escolarização às crianças pequenas etc. Nesse quadro, as apresentações e mostras culturais podem funcionar como um tipo de "prova" dessa suposta "produtividade". Reafirmando a importância de partilhar o trabalho com os diferentes atores sociais envolvidos (crianças, profissionais, familiares e comunidade), buscando alternativas de diálogo que possam refletir sobre as ações educativas mobilizadas com as crianças, salientamos que essa é uma questão complexa, cuja análise em profundidade não cabe nos limites deste texto.

Continuando a análise dos eventos que se referem aos movimentos institucionais mais coletivos, envolvendo a participação dos bebês, apresentamos dados relativos a uma festa em comemoração ao dia da criança:

[...] Teve pula-pula, cama-elástica, pipoca, algodão doce etc. Logo, entramos no fluxo da instituição e ajudamos as professoras e auxiliares a cuidar e a brincar com as crianças. Nesse dia percebemos como o cuidar pode 'aprisionar' as crianças. A equipe tem a obrigação de garantir (entre outras coisas) a integridade física das crianças e para isso é muito mais cômodo proibir que elas façam coisas do que apoiá-las com atenção, por exemplo, separar as crianças pequenas das maiores, para evitar acidentes[...]. Então, para evitar esse tipo de situação, é mais fácil restringir várias coisas às crianças pequenas (R E; 13 de outubro de 2014).

A garantia da proteção, resguardando a integridade física das crianças, precisa ser combinada com a garantia da brincadeira e da experimentação de coisas novas. A interação entre as crianças de faixa etária diferente é uma boa oportunidade para que elas construam redes de troca de saberes, observando que "[...] bebês e crianças bem pequenas aproveitam a companhia de crianças maiores [...] crianças maiores aprendem muito observando e ajudando a cuidar de bebês e crianças pequenas" (BRASIL, 2009, p. 22).

Voltando aos nossos movimentos mais internos ao coletivo dos bebês, buscamos um exercício com a linguagem musical que é, ao mesmo tempo, teatral, pois, como aponta Slade (1978), o jogo dramático também é projetado. Em nosso caso interativo com os bebês, movemos uma interação com o violão: 
[...] levamos um violão para mostrar para os bebês, com a intenção de interagir com eles, apresentando algo diferente das coisas que tem na sala. Os bebês adoraram, todos interagiram, eles batucavam com o violão, puxavam as cordas, desafinavam, queriam sentar em cima, enfim, testar todas as possibilidades que aquele objeto novo poderia proporcionar, assim como os diferentes sons que ele produz. Só não conseguimos tocar nada para eles, pois eles não deixaram, eles seguraram a mão... Nesse primeiro momento com o objeto, a interação direta era mais importante do que a suposta contribuição de poder tocar para eles (R E; 13 de outubro de 2014).

Essa experiência ratificou a observação de que os bebês estão interessados em experimentar as múltiplas possibilidades de se utilizar os objetos, interagindo com eles, criando sua própria maneira de manipulá-los, a despeito da nossa pretensão adulta de informar-lhes a maneira "correta" de utilização das coisas. Com o nosso processo formativo vivenciado, assinalamos a importância de estabelecer relações com os bebês que possibilitam o exercício das ações, pois

[...] é nossa relação que define o objeto e sua estrutura e não o contrário; só onde a relação se torna aleatória de nossa parte, meio caprichosa, e nos afastamos da nossa relação de princípio com as coisas e com o mundo, a determinidade do objeto resiste a nós como algo estranho e independente e começa a desagregar-se, e nós mesmos ficamos sujeitos ao domínio do aleatório, perdemos a nós mesmos e perdemos também a determinidade estável do mundo (BAKHTIN, 2011, p. 4).

O violão só se objetivou a partir da interação e experimentação dos bebês. As práticas pedagógicas para se constituírem como algo potente na vida da criança devem permitir a iniciativa delas de se relacionarem com o objeto. "A criança pequena, ao deparar-se com algo do mundo externo que não compreende, jogará com isso dramaticamente até que possa compreendê-lo" (COURTNEY, 1980, p. 4). Assim, a curiosidade é fortíssima nos bebês, implica conhecimento do mundo.

Considerando o conjunto de dados reunidos na pesquisa que indicam a expectativa dos adultos (inclusive a dos pesquisadores, ainda que sempre questionada a partir dos referenciais) de conseguir reunir os bebês em ações mais coletivas, assinalamos que o conhecimento, movido pela experimentação com as coisas do mundo, pode ser potencializador dos agrupamentos na mesma ação. No caso do evento com o violão, cabe observar que os agrupamentos permitem identificar um foco de ação que agrega distintas particularidades de processos interativos. Assim, a proposição de atividades coletivas precisa considerar as diferentes possibilidades de engajamento e participação, das mais próximas às mais afastadas, observando as sutilezas de interagir com o mundo, integrando objetos e parceiros de ação.

Mirando mais detidamente os parceiros de ação, como mobilizadores dos processos interativos, processualmente, nós e os bebês fomos ficando mais próximos, possibilitando registrar dados. Eles nos chamavam a todo tempo para brincar e nos recebiam com abraços assim que chegávamos à sala. Nesse movimento comum, com os aprendizados formativos carreados no curso da pesquisa, destacamos mais uma atividade partilhada, chamada "o balão como prolongamento do corpo" (BOAL, 2008). O jogo consiste em manter um ou vários balões de ar no alto, usando as mãos, os pés ou qualquer outra parte do corpo.

Para interagir com os bebês, utilizamos apenas um balão, participando ativamente com eles, mantendo o balão no alto sem deixar cair. Quase todos participaram, dois ficaram 
com medo do balão [...]. Uma se escondeu debaixo de uma mesa que tem na sala, e o outro, apesar do medo, estava sempre perto. Ele estava curioso, mas não queria tocar no balão. Pensando em evitar que alguma criança chorasse por causa do balão, enchemos o balão na frente deles, com eles segurando, depois esvaziamos, de modo que pudessem experimentar com o balão cheio e também vazio (R E; 24 de outubro de 2014).

Tivemos a preocupação de introduzir o balão na brincadeira de modo que as crianças pudessem ter contato prévio com o objeto, ainda que, possivelmente, o balão não fosse um objeto alheio aos universos infantis. Ainda assim, dois bebês não quiseram brincar com o coletivo que se estabeleceu. Portanto, é preciso entender que não precisamos, necessariamente, trabalhar com todos os bebês juntas em uma mesma atividade.

Depois de alguns minutos com o balão no alto, os bebês começaram a querer agarrar o balão, [...] até que, em certo momento, dois bebês agarraram o balão ao mesmo tempo. Claro que o balão não aguentou e estourou, mas os dois bebês não choraram, permaneceram estáticos olhando um para o outro, meio que sem entender direito o que havia acontecido (R E; 24 de outubro de 2014).

Com os aprendizados da pesquisa, buscamos reposicionar a lógica de propor atividades que envolvessem toda a turma, implicando parar o fluxo cotidiano das crianças para exigir uma atenção para a possibilidade de mover experiências de brincadeiras coletivas, ampliando os grupos de participação, sem, contudo, buscar abarcar a totalidade dos bebês. Cabe observar as distintas formas de aprendizados, inclusive assistindo aos colegas. Foi possível captar observações de crianças que, mesmo não participando de determinada ação, se manifestaram na avaliação do seu desfecho, por exemplo, das motivações para que o balão tenha estourado ou porque não conseguisse ser mais enchido de ar.

No caso da interação com o balão, nosso objetivo não era torná-los mestres em manter o balão no ar, mas vivenciar possibilidades de considerar os vários elementos presentes nessa experiência. Quando o balão estourou, os bebês se olharam, em silêncio, depois um deles olhou para nós e disse "Pocô". Nesse momento, pela entonação ${ }^{9}$ presente na palavra e na troca de olhares, foi possível perceber que eles tiveram uma experiência significativa, pois "Se uma palavra isolada é pronunciada com entonação expressiva, já não é uma palavra, mas um enunciado acabado expresso por uma palavra" (BAKHTIN, 2011, p. 290).

Esse enunciado, para nós, representa o quanto conseguimos estar integrados à experiência, também com a nossa singularidade de termos introduzido o balão, afinal foi a nós o endereçamento da discursividade do problema ocasionado com o fim do balão. Desse modo, as crianças são abertas aos processos interativos, acolhendo vários parceiros nos percursos de trabalho conjunto. No desenrolar de nossas aprendizagens de pesquisa, afirmamos que fomos desenvolvendo "um clima de proximidade" que possibilitou uma "comunicação alargada", tanto nos dirigindo às crianças, quanto sendo chamados por elas nas várias demandas que emergem na conviviabilidade cotidiana da instituição (R E; 7 de novembro de 2014).

${ }^{9}$ Conceito bakhtiniano. Entonação é o conjunto de valores que imprimimos nos signos, dando sentido e forma ao enunciado. 
Assim, os processos interativos sustentados em proximidades comuns parecem favorecer a proposição de "coisas novas", indicando que também os adultos precisam ser acolhidos numa negociação comum das atividades a serem realizadas. Uma observação muito importante da pesquisa, para nós, é que a riqueza do trabalho com os bebês informa que eles não se furtam às manifestações. Seja nas adesões, seja nas recusas (sem proposição de dualismos, pois integram muitas outras formas de dizer), o referencial bakhtiniano permite assinalar o quanto as crianças pequenas estão mobilizadas em seus dizeres, informando sua participação ativa no fluxo das ações. Nessa perspectiva, já no final do ano letivo, propusemos uma brincadeira chamada "dança com maçã" (BOAL, 2008), que consiste em dois parceiros tentar andar ou dançar com uma maçã entre suas cabeças e não deixá-la cair. Para realizar essa atividade com os bebês, utilizamos uma pequena bola de plástico, que pertence à escola.

Chamei um dos bebês para brincar comigo [...]. Conseguimos manter a bola entre nossas cabeças por um bom tempo, enquanto nos movíamos. Quando a bola caiu, todos os bebês riram, acharam o máximo, logo todos queriam brincar comigo. Brinquei com cada um deles, mas não queria apenas interagir com eles, queria que eles interagissem entre si. Propus a um dos bebês que brincasse com um dos colegas e ele aceitou de imediato, logo todas estavam brincando (R E; 7 de novembro de 2014).

A expressão feliz dos bebês transparecia a alegria em brincar com algo tão simples, que até então não tinha muita utilidade na sala, pois parece que já estava meio repetitivo jogar com as mãos ou chutar com os pés as bolas disponíveis. Para executar essa ação, aproveitamos a intimidade com o primeiro convidado, compondo uma demonstração inicial de uma nova brincadeira. Uma demonstração que pode ser rememorada com outros parceiros e, posteriormente, vivenciada simultaneamente com várias duplas compostas de forma aleatória. Movimentos de, conjuntamente, compor uma parceria de trabalho, visando a um objetivo comum, brincar com a bola de um modo diferente que, para nós, adultos, significava manter a bola entre as cabeças.

Dessa forma, o aprendizado não se deu apenas na desenvoltura de não deixar a bola cair, ainda que ela pudesse se mover entre as cabeças, mas de observar as motivações que a fizeram cair, de encaminhar maneiras de resgatar as bolas, de encontrar formas de movimentação que não fosse ficar parado (ficando desinteressante a experiência) e, com mais destaque, conseguir compor parcerias para a execução da brincadeira. As parcerias formadas puderam ser fortalecidas, repetindo as execuções, quanto redimensionadas, em fluxos que falam dos vários processos comunicativos que podem se estabelecer numa coletividade. Em relação a nós, fomos instados a brincar com cada um e, em muitos casos, repetindo a experiência comum, ganhando as avaliações de assistentes, contando com sugestões para melhor desempenho etc.

Reiterando que a sutileza é uma das especificidades do trabalho pedagógico (BARBOSA, 2010), ainda que nosso referencial não abarque o destaque para proporcionar experiências construtivas (no sentido de mover produtividades) por meio da arte, mas procure evidenciar as experimentações, talvez em função dos dados que retratam nossas desventuras iniciais, não podemos negar a satisfação com o "sucesso" das atividades, marcando a observação de que "[...] havíamos conseguido fazê-los brincar 
juntos, mobilizá-los numa coletividade comum, encaminhado ações partilhadas...” (R. E; 7 de novembro de 2014).

Esse dado nos parece importante para considerar os processos formativos partilhados entre adultos e bebês no curso das práticas pedagógicas desenvolvidas nos contextos institucionais. A necessidade de respeitar as especificidades e singularidades das crianças pequenas, com suas demandas, só se efetiva instando também a análise das expectativas dos adultos nesse encontro que, não sem tensões, promovem os processos formativos de todos os envolvidos. Abarcar a sutileza deste trabalho implica considerar também as aprendizagens que os bebês movem a despeito das proposições dos adultos e da importância do apoio às iniciativas das crianças, da observação do ambiente (físico e social) como mobilizador do curso das ações. Questões que não minimizam o papel dos professores, reposicionando com maior complexidade as formas de atuação, de modo a convidar à experimentação de outras lógicas de ação que se sustentem no diálogo entre adultos e crianças.

\section{Considerações finais}

Conforme assinalamos, compusemos uma pesquisa buscando experiências compartilhadas com os bebês e, com isso, movemos processos formativos que assinalam - não sem dificuldades e tensões possibilidades de fazer junto com as crianças. Todavia, essa lógica desestabiliza pressupostos tradicionais da docência, convidando novas formas de constituição do trabalho educativo com as crianças, em especial, considerando as demandas dos bebês.

As ações pautadas nos princípios de parceria e de interação, sempre dialógicas com os bebês vivificam-se na reflexão de que podemos brincar com eles, dando importância às suas demandas e propostas, compondo um movimento comum em que eles também respondem aos nossos convites de modo que nos juntemos em descobertas. Eles, agregando conhecimentos das coisas no mundo, e nós, dos processos educativos com eles nas coisas do mundo (assimilando novos conhecimentos de nossas possibilidades docentes). Nesse jogo de compor a vida comum, as práticas pedagógicas envolvem uma gama variada de objetos e formas de ação que incluem movimentos mais individuais, parceiras variadas e possibilidades mais coletivas. Todavia, não se trata de uma massificação hierárquica em que os tempos das crianças são regulados pelas ordenações dos adultos. Com isso, atentar às sutilezas da vida comum em que os bebês podem realizar atividades individualmente, dirigir-se a um outro próximo, integrar grupos coletivos etc. de modo a considerar que os distintos fluxos podem trazem aprendizagens ainda que distintas, é igualmente importante para a diversidade da vida.

Para finalizar, cabe destacar que estar com os bebês é sempre muito formativo. Literalmente nos constituiu como profissionais da educação infantil na relação com o nosso outro, no caso, os bebês. Nesse sentido, este trabalho que, a princípio, era sobre as práticas pedagógicas, aos poucos se transformou em uma pesquisa sobre a formação docente. Nesse contexto, tornamo-nos sujeitos da nossa própria pesquisa, buscando compor os dados sem medo de expor os "erros". Mais do que isso, de informar as tentativas 
que movemos na dialogia com os bebês, ou melhor, as tentativas movidas com os processos formativos instados no encontro com os bebês, acreditando nas possibilidades de construir uma educação infantil de qualidade para os bebês e seus docentes. 


\section{Referências}

BAKHTIN, M. M. Estética da criação verbal. 6. ed. São Paulo: Editora WMF Martins Fontes, 2011.

.Marxismo e filosofia da linguagem: problemas fundamentais do método sociológico na ciência da linguagem. 13. ed. São Paulo: Hucitec, 2012.

BARBOSA, M. C. As especificidades da ação pedagógica com bebês. Disponívelem: $<$ http:/ $/$ portal.mec.gov.br/index.php?Itemid=1096\&id=15860\&option=com content\&vie $\underline{\mathrm{w}}=$ article $>$. Acesso em: 21 out. 2011.

BOAL, A. Jogos para atores e não atores. 11. ed. Rio de Janeiro: Civilização Brasileira, 2008.

BRASIL. Lei Federal n. ${ }^{\circ}$ 9.394, de 20 de dezembro de 1996. Estabelece as diretrizes e bases da educação nacional. Disponível em: <https://www.planalto.gov.br/ccivil_03/Leis/L9394.htm>. Acesso em: 21 out. 2011

. Ministério da Educação. Critérios para um atendimento em creches que respeite os direitos fundamentais das crianças. Brasília: MEC, 2009.

. Ministério da Educação. Diretrizes curriculares nacionais para a educação infantil. Brasília: MEC, 2010.

CERTEAU, M. de. A invenção do cotidiano: artes de fazer. 17. ed. Rio de Janeiro: Vozes, 2011.

COURTNEY, R. Jogo, teatro e pensamento. São Paulo: Perspectiva, 1980.

FARIA FILHO, L. M. et al. A cultura escolar como categoria de análise e como campo de investigação na história da educação brasileira. Educação \& Pesquisa, v. 30, n. 1, jan./abr. 2004.

KOUDELA, I. D. Jogos teatrais. 7. ed. São Paulo: Perspectiva, 2011.

MOREIRA, H; CALEFFE, L. G. Metodologia da pesquisa para o professor pesquisador. 2. ed. Rio de Janeiro: Lamparina, 2008.

SLADE, P. O jogo dramático infantil. 2. ed. São Paulo: Summus Editorial, 1978.

SPOLIN, V. Improvisação para o teatro. São Paulo: Perspectiva, 1979.

STAM, R. Mikhail Bakhtin e a crítica cultural de esquerda. In: KAPLAN, E. A. (Org.). O mal-estar no pós-modernismo:teorias e práticas. Rio de Janeiro: Jorge Zahar, 1993. p. 149-184.

VOLOCHÍNOV. V. N. A palavra na vida e a palavra na poesia. In: VOLOCHÍNOV. V. N. A construção da enunciação e outros ensaios. São Carlos: Pedro \& João Editores, 2013. 
VIGOTSKY, L. S. Imaginação e criação na infância: ensaio psicológico: livro para professores. São Paulo: Ática, 2009.

PINO, A. As marcas do humano: as origens da constituição cultural da criança na perspectiva de Lev S. Vigotski. São Paulo: Cortez, 2005. 